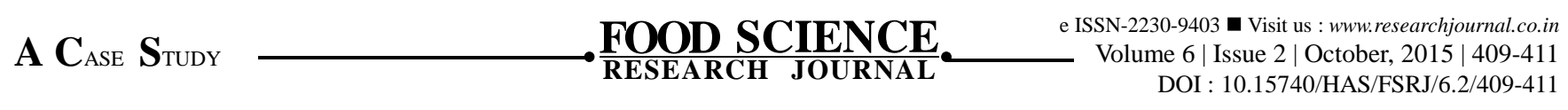

\title{
Effects of bael fruit on gastrointestinal disorder
}

\author{
Punam Agarwal and T. Gayatri
}

The fast paced lifestyle of our modern times takes a toll on everybody's health. Irregular eating habits, increasing pollution, consumption of fast food and extreme change in climate lead to many gastro intestinal disorders and Diarrhoea is one of the most common of them.It is defined as increase in frequency of stool (watery) and sometimes a sense of fecal urgency . A person suffering from diarrhea has loose motions more than 3 times a day. The present study was conducted on Diarrhoea patients to check the effect of Bael fruit in relieving from the same. The fruit was supplemented in different ways and the subjects chosen for the study were divided into groups according to the severity (severe, 8-10 times and moderate 4-6 times) of loose motions. It was seen that there was very successful reduction in the number of stools per day. So it was concluded that Bael fruit is a very healthy, nutritious and safe option in controlling Diarrhea without any side effects.

Key Words : Bael fruit, Gastrointestinal disorder

How to cite this article : Agarwal, Punam and Gayatri, T. (2015). Effects of bael fruit on gastrointestinal disorder. Food Sci. Res. J., 6(2): 409-411.

Author for correspondence :

PUNAM AGARWAL, College of Home Science, Orissa University of Agriculture, BHUBANESWAR (ODISHA) INDIA

Associate Authors' :

T. GAYATRI, Utkal University, BHUBANESWAR (ODISHA) INDIA 